\title{
JEAN DE LA FONTAINE, Relation d'un voyage de Paris en Limousin (1663)
}

\section{Federico Corradi}

\section{(2) OpenEdition}

\section{Journals}

\section{Edizione digitale}

URL: https://journals.openedition.org/studifrancesi/23447

DOI: 10.4000/studifrancesi.23447

ISSN: 2427-5856

\section{Editore}

Rosenberg \& Sellier

\section{Edizione cartacea}

Data di pubblicazione: 1 avril 2020

Paginazione: 169-170

ISSN: 0039-2944

\section{Notizia bibliografica digitale}

Federico Corradi, «JEAn de LA FontaINE, Relation d'un voyage de Paris en Limousin (1663)», Studi Francesi

[Online], 190 (LXIV | I) | 2020, online dal 01 mai 2020, consultato il 03 août 2021. URL: http://

journals.openedition.org/studifrancesi/23447 ; DOI: https://doi.org/10.4000/studifrancesi.23447

Questo documento è stato generato automaticamente il 3 août 2021.

\section{$\circledast \oplus \Theta \Theta$}

Studi Francesi è distribuita con Licenza Creative Commons Attribuzione - Non commerciale - Non opere derivate 4.0 Internazionale. 


\title{
JEAN DE LA FONTAINE, Relation d'un voyage de Paris en Limousin (1663)
}

\author{
Federico Corradi
}

\section{NOTIZIA}

JEAN DE LA FONTAINE, Relation d'un voyage de Paris en Limousin (1663), texte établi, présenté et annoté par D. Fortin, Paris, Hermann, 2018, «Bibliothèque des Littératures classiques», $190 \mathrm{pp}$.

1 «Ce serait une belle chose que de voyager, s'il ne fallait point se lever si matin»: l'incipit di una delle sette lettere indirizzate da La Fontaine a sua moglie tra agosto e settembre 1663 nel corso del suo viaggio in Limousin esemplifica bene il tono di badinerie, a tratti un po' insipido, che caratterizza quest'opera. Al punto che a tutta prima si è tentati di vedere in questa relazione di viaggio una semplice bagatelle, non diversa per tenore dalla prima produzione poetica di La Fontaine, quei versi d'occasione legati all'ambiente di Fouquet che certamente non basterebbero ad assicurare la reputazione del poeta. Eppure la Relation d'un voyage de Paris en Limousin è a suo modo un testo chiave, soprattutto per il momento in cui è stato scritto. Cronologicamente, esso si situa tra la stesura dei frammenti superstiti del Songe de Vaux, avvenuta nel corso del 1661, e la pubblicazione della prima plaquette di Contes nel 1664. A separare queste due opere c'è l'arresto del Surintendant, drammatico evento politico-giudiziario che segna, com'è noto, una cesura nella vita di La Fontaine: esso rende certo più fragile la sua posizione sul piano economico e istituzionale, ma consente anche alla sua vena poetica di compiere un evidente scatto di qualità. Secondo le ipotesi più recenti, infatti, è proprio tra il 1663 e il 1664 che La Fontaine avrebbe composto non solo le prime novelle in versi, ma anche le prime favole, identificando quindi i due generi che gli avrebbero assicurato la gloria letteraria negli anni a venire. È naturale quindi - e gli interpreti di La Fontaine non hanno mancato di farlo - cercare in questo scarno epistolario tracce di questa maturazione poetica e umana. Eppure, quando si tenta di dare un significato più ampio ad alcune affermazioni nascoste nelle pieghe del testo, ci si scontra con la 
leggerezza - apparente o reale? - di cui parlavo. Ed è questo a mio avviso il principale, ma non l'unico, elemento di enigmaticità di quest'opera: la maschera difensiva che La Fontaine indossa proprio quando fa di se stesso l'oggetto della sua scrittura. Non stupisce che Marc Fumaroli, applicando alla Relation lo schema straussiano dell'écriture réticente, vi abbia potuto leggere tra le righe i principi (criptati) di un vero e proprio manifesto estetico-politico: in particolare, attraverso la descrizione in successione del castello di Blois e della dimora di Richelieu, La Fontaine contrapporrebbe alla "diversité ingénieuse et vivante" del primo, ancora legata al gusto rinascimentale, la regolarità monotona e grigia del secondo, che annuncia il severo classicismo louis-quatorzien. Le due dimore diverrebbero emblema, quindi, dell'opposta filosofia politica dei rispettivi proprietari: da una parte il rispetto di Gaston d'Orléans per la diversità e le libertà fondamentali del regno, dall'altra la logica fredda e accentratrice dell'assolutismo monarchico promosso dal Cardinale. Vista in questa prospettiva, la Relation diventa ovviamente una testimonianza decisiva per avvalorare la tesi che vede in La Fontaine un "résistant intérieur" contro la svolta autoritaria del giovane Luigi XIV.

2 La scelta di Damien Fortin, curatore di questa nuova e documentatissima edizione del testo, è più prudente. Pur dando il giusto risalto ai passi che testimoniano della riflessione larvatamente politica del futuro favolista, non trascura la componente di puro divertissement e di sperimentazione formale che contengono queste lettere, scritte probabilmente per essere lette non solo da Marie Héricart, ma anche da una ristretta cerchia di amici e conoscenti del poeta. Nella ricca introduzione, il curatore passa innanzitutto in rassegna, documenti alla mano, le diverse ipotesi sulle ragioni del viaggio, che restano avvolte nel mistero: esilio imposto dall'autorità monarchica o viaggio intrapreso liberamente per accompagnare lo zio Jannart costretto ad allontanarsi da Parigi? Poi inserisce l'opera in un filone narrativo, il récit de voyage, molto in voga in quegli anni, che lo stesso La Fontaine presenta come compromesso tra l'"histoire" - si tratta infatti di un récit factuel che dà ampio spazio alla descrizione e all'informazione sui luoghi attraversati dal narratore - e il "roman" - il divertissement è assicurato dai numerosi aneddoti e piccole avventure picaresche di cui il resoconto si arricchisce. Questa duplice componente, erudita e leggera, riconduce naturalmente il progetto all'ambito dell'estetica galante, confermata dalla scelta del prosimetro, già praticato da La Fontaine nel Songe de Vaux e da Sarasin nella Pompe funèbre de Voiture. All'estetica galante si conforma anche il tono particolare dell'opera, che esita costantemente tra tentazione elegiaca e raillerie, e passa in rassegna, per parodiarli, i più diversi generi. La Fontaine, del resto, dispone di modelli prestigiosi, che vanno dall'Iter Brundisinum di Orazio al più recente Voyage d'Encausse di Chapelle e Bachaumont. È in questa scelta di poikilia, in questa pratica sapiente del décalage e dei contrasti di tono che vediamo a tratti apparire dietro il narratore della Relation "épicurien subtil", "touriste désinvolte" - il futuro virtuoso poeta delle Fables.

Questa nuova edizione fa il punto quindi sui principali problemi critici e interpretativi sollevati da quest'opera e aggiunge al già noto una ricchissima messe di informazioni di carattere storico, biografico e bibliografico nell'apparato di note che correda il testo. Costituisce quindi uno strumento prezioso per penetrare nelle pieghe di uno dei testi più sfuggenti e affascinanti di La Fontaine. 